\title{
Tren Milenial Memilih Jurusan Di Perguruan Tinggi Menggunakan Metode Social Network Analysis
}

\author{
Millennial Trends to Choose Majors In College using Social Network Analysis Method \\ Indri Febrianti ${ }^{1}$, M.Khairul Anam ${ }^{2}$, Rahmiati ${ }^{3}$, Tashid ${ }^{4}$ \\ 1,2,3,4 Program Studi Teknik Informatika, STMIK Amik Riau \\ Email: ${ }^{1}$ Ifebrianti97@gmail.com, ${ }^{2}$ khairulanam@sar.ac.id, ${ }^{3}$ rahmiati@ stmik-amik-riau.ac.id, \\ ${ }^{4}$ tashid@stmik-amik-riau.ac.id
}

\begin{abstract}
Abstrak
Perguruan tinggi merupakan jenjang pendidikan yang tertinggi di Indonesia. Perguruan tinggi di Indonesia memiliki banyak jurusan atau program studi akan tetapi hampir seluruhnya memiliki program studi yang sama. Calon mahasiswa yang akan masuk perguruan tinggi pada saat ini lebih kenal dengan sebutan generasi milenial. Twitter merupakan media social yang sering digunakan oleh generasi milenial, pihak perguruan tinggi harus bisa memanfaatkan celah yang ada dari media sosial dengan cara melihat dan mengamati minat generasi milenial saat ini. Akan tetapi permasalahan yang dihadapi perguruan tinggi tidak dapat memanfaatkan media sosial dengan efektif dan tidak mengetahui keinginan calon mahasiswa, sehingga banyaknya mahasiswa yang putus kuliah karena skill yang mereka punya tidak dapat disalurkan dengan baik. Penelitian ini menggunakan Social Network Analysis (SNA) agar dapat diaplikasikan untuk menganalisa dan memberikan informasi yang dibutuhkan oleh perguruan tinggi mengenai jurusan yang sedang tren di kalangan generasi milenial. Hasil dari penelitian ini yaitu jurusan yang sering mendapatkan nilai tertinggi adalah teknik informatika dengan hasil lima dari tujuh nilai tertinggi dalam perhitungan properti jaringan.dari hasil yang telah didapatkan perguruan tinggi yang memiliki jurusan teknik informatika bisa memanfaatkan media social dengan melihat minat calon mahasiswa dalam memilih matakuliah di jurusan teknik informatika.
\end{abstract}

Kata kunci: Perguruan Tinggi, Jurusan, Generasi Milenial, Media Sosial, Sosial Network Analysis.

\begin{abstract}
College is the highest level of education in Indonesia. College institutions in Indonesia have many majors or study programs but almost all have the same study program. Prospective students who will enter college at this time are more familiar with the term millennial generation. Twitter is a social media that is often used by millennials, universities must be able to take advantage of existing gaps in social media by looking at and observing the interests of today's millennial generation. However, the problems faced by tertiary institutions cannot utilize social media effectively and do not know the wishes of prospective students, so that many students drop out because their skills cannot be properly channeled. This study uses Social Network Analysis (SNA) so that it can be applied to analyze and provide information needed by universities about majors that are trending among millennials. The results of this study are majors that often get the highest score is informatics engineering with the results of five of the seven highest scores in the calculation of network properties. From the results obtained by universities that have majoring in informatics engineering can utilize social media by looking at the interests of prospective students in choosing courses majoring in informatics engineering.
\end{abstract}

Keywords: Collage, Majors, Millennial Generation, Social Media, Social Network Analysis 


\section{PENDAHULUAN}

Perguruan tinggi adalah tahap selanjutnya yang akan ditempuh setelah tamat dari bangku pendidikan menengah, yang mencakup program pendidikan diploma, sarjana, magister, dll yang diselenggarakan oleh perguruan tinggi yang dinyatakan dalam UU No. 20 tahun 2003 pasal 19 ayat 1 [1]. Setiap perguruan tinggi memiliki beberapa jurusan atau program studi yang sama.Karna banyaknya program studi yang sama maka perguruan tinggi saling berkopetensi dalam mengembangkan seluruh kekuatan dan kemampuannya guna menarik minat calon mahasiswa. Di samping semakin selektifnya kompetisi antar perguruan tinggi, masalah lain yang timbul yaitu semakin kritisnya calon mahasiswa dalam mengambil keputusan untuk memilih sebuah perguruan tinggi, yang mana calon mahasiswa saat ini lebih kita kenal dengan nama generasi milenial. Pihak perguruan tinggi perlu mengatur strategi pemasaran untuk memenangkan persaingan dengan salah satu cara yaitu melihat tren generasi milenial untuk memilih jurusan.

Generasi milenial adalah generasi yang lahir awal tahun 1980 hingga tahun 2000. Generasi ini banyak menggunakan teknologi komunikasi media sosial seperti facebook, twitter, instagram dan lain-lain [2]. Selain itu, umumnya generasi milenial selalu ingin sesuatu yang ideal. Misalnya dalam masalah pemilihan jurusan di perguruan tinggi, generasi milenial pasti selalu mau dapat tempat kuliah yang sesuai dengan passion-nya.

Pihak perguruan tinggi harus bisa melihat celah yang dapat dimanfaatkan dari media sosial dengan cara melihat dan mengamati minat generasi milenial saat ini, yang mana sedang tren di kalangan milenial saat ini yaitu Conten Creator dan Games [3]. Pihak perguruan tinggi bisa membuat sebuah strategi terobosan dengan memanfaatkan tren milenial saat ini seperti membuka sebuah program studi (prodi) baru atau menambah mata kuliah yang berkaitan dengan conten creator dan games. Pada tahun 2018 Kementerian Riset dan Pendidikan Tinggi (Kemenristekdikti) RI mencatat sebanyak 245.494 mahasiswa yang putus kuliah [4]. Salah satu penyebab putus kuliah yaitu banyak kasus mahasiswa yang merasa tidak searah dengan minatnya ketika ia telah mendapatkan materi kuliah di perguruan tinggi, sehingga menyebabkan mahasiswa mengambil keputusan berhenti kuliah [5].

Menghadapi kondisi yang telah diuraikan, maka perguruan tinggi membutuhkan sebuah analisa yang bisa menampilkan graph untuk mengetahui tren jurusan yang popular dikalangan generasi milenial saat ini. Interaksi yang terjadi di dalam proses pembicaraan mengenai pemilihan jurusan kalangan milenial di Indonesia pada sosial media twitter mengambarkan sebuah jaringan penyebaran informasi yang mana jika dianalisis maka akan mendapatkan hasil sebuah informasi yang berguna bagi perguruan tinggi untuk membuat sebuah terobosan membangun jurusan baru atau menambah matakuliah dari hasil yang telah diamati melalui Social network analysis.

SNA adalah ilmu yang mempelajari hubungan antar satu unit entitas dengan unit entitas lainnya dengan bantuan teori graph [6]. Metode dan teknik SNA ini dipilih karena penelitian ini membutuhkan sebuah metode yang dapat memberikan sebuah gambaran atau visualisasi di dalam jaringan sesuai dengan data yang telah dilakukan preprocessing, metode SNA ini juga dapat digunakan untuk menemukan node, communities, dan informal hierarchies yang memiliki pengaruh paling besar di dalam jaringan [7].

Tujuan menggunakan metode ini diharapkan dapat membantu mengolah data dan membuat sebuah analisa yang menghasilkan graph agar pihak perguruan tinggi bisa memanfaatkan graph untuk lebih melihat celah jurusan yang popular di kalangan milenial.

\section{METODE PENELITIAN}

Penelitian dalam pemilihan data dan informasi bersifat objektif yang digunakan sebagai titik acuan untuk penelitian, dengan adanya data-data tersebut penelitian yang di hasilkan adalah penelitian yang berkualitas. Proses penelitian ini digambarkan pada Gambar 1. 


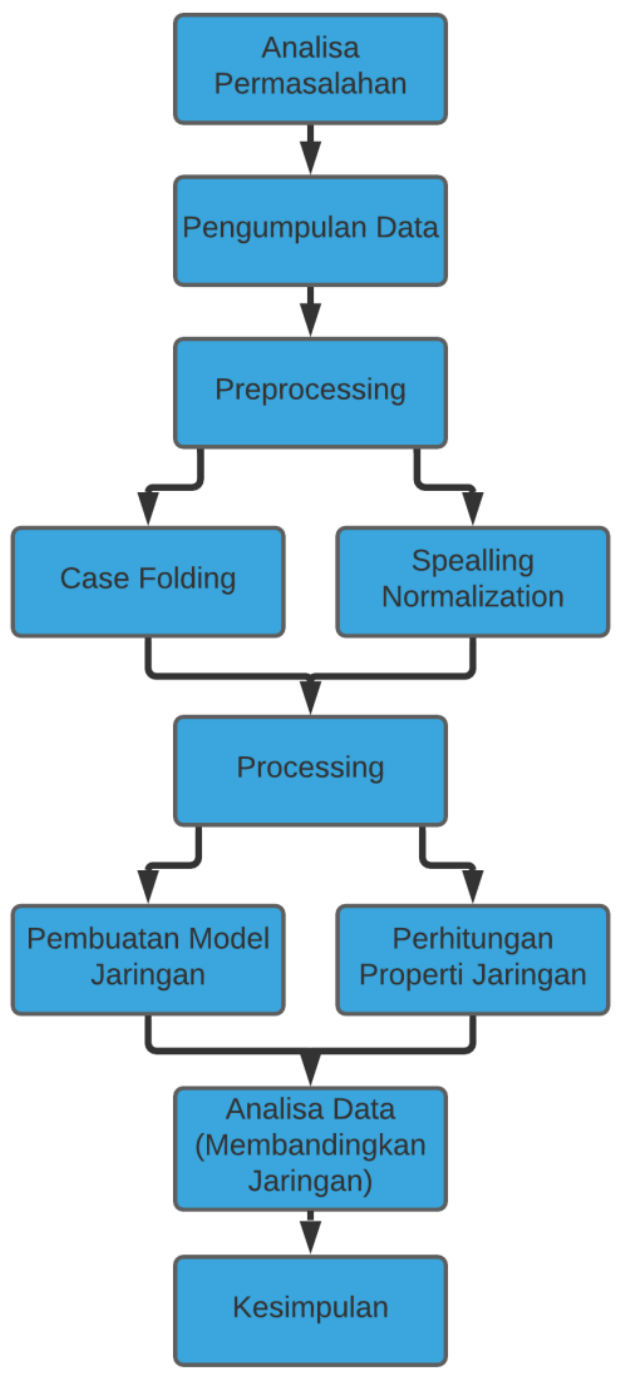

Gambar 1 Alur Metodologi Penelitian

\subsection{Tahap Analisa Permasalahan}

Tahap analisa dilakukan menggunakan metode Social Network Analysis karena tujuan dari penelitian ini adalah dapat menganalisasi keaktifan percakapan di media sosial twitter mengenai jurusan yang ada di Indonesia, menentukan jurusan mana yang sering dibicarakan agar dapat membantu pihak perguruan tinggi untuk melihat trend jurusan yang diminati oleh generasi milenial pada saat ini sehingga bisa mengurangi angka putus kuliah.

\subsection{Tahap Pengumpulan Data}

Pengumpulan data mengenai jurusan yang trend dikalangan generasi milenial saat ini di ambil dengan menggunakan media sosial yang berisikan konten-konten yang dibuat oleh user. Media yang digunakan sebagai sumber data adalah media sosial twitter dengan tweet sebagai konten data yang diambil. Data yang diambil yaitu seluruh tweet baik berupa retweet, reply, maupun mention yang berisi kata kunci 'nama jurusan'. Kata kunci ini dipilih karna langsung kepada topik yang diteliti dan tidak akan menimbulkan multi-tafsir dengan topik lain. Apabila menggunakan kata kunci lain berupa frasa dengan operator penghubung $A N D$ akan membuat hasil dari pencarian semakin sempit dan tidak dapat mengambarkan keadan lebih umum dengan topik yang akan di crawling. Sedangkan jika mengunakan frasa dengan operator $O R$ akan membuat hasil pencarian data tidak sesuai dengan yang akan kita teliti. Pengumpulan data dalam peneltian diambil dengan rentang waktu dari juli 2019 sampai maret 2020. Pengumpulan data dilakukan 
menggunakan software python. Selanjutnya data yang diperoleh dalam bentuk CSV yang masih memiliki dimensi yang tinggi terdapat noise pada data, dan terdapat struktur teks yang tidak baik. Maka dilakukan proses preprocessing agar atribut-atribut yang tidak perlu dapat dihilangkan agar sisa data sesuai dengan kebutuhan penelitian sehingga data lebih mudah untuk dianalisis.

\subsection{Tahap PreProcessing}

Tahap text preprocessing adalah tahap awal yang dilakukan. Tahap ini meliputi proses pengolahan data mentah untuk menjadi data yang bisa berguna dalam menyelesaikan permasalahan yang di lakukan dalam penelitian. [8]. Tahapan-tahapan yang dijalankan dalam text preprocessing yaitu Cleaning, Case folding, Tokenizing, Spelling normalization, Filtering, Stemming.

Dalam penelitian ini tindakan yang dilakukan pada proses preprocessing dilakukan 2 tahap karna data hasil dari crawling dari twitter hanya di perlukan nama jurusan dan nama user sehingga proses preprocessing yang dibutuhkan yaitu Case Folding, mengubah karakter huruf yang ada didalam data menjadi sama seperti huruf kecil semua selanjutnya Spelling Normalization berfungsi untuk mengidentifikasi kalimat yang berlebihan atau kata yang disingkat diganti dengan ketentuan kata yang ada.

\subsection{Tahap Processing}

Tahapan yang ada dalam Processing adalah:

\section{Pembuatan Model Jaringan}

Tweet yang telah ter-filter dari hasil preprocessing data kemudian diproses lebih lanjut untuk dibuat visualisasi model jaringan sesuai dengan penelitian yang dilakukan pembuatan model jaringan ini berfungsi untuk mengetahui seberapa besar aktor-aktor yang berinteraksi satu sama lain sehingga dari interaksi tersebut dapat membagun sebuah jaringan jurusan yang trend dikalangan generasi milenial saat ini. Pembuatan model jaringan yang dilakukan menggunakan jenis Undirected Graph, yaitu graph yang tidak memperhatikan arah hubungan pada node. Jenis graph ini tidak terdapat indegree (node yang dituju) dan outdegree (node asal).

Ada beberapa konsep di dalam pendekatan social network analysis, selain meggambarkan pola yang terbentuk dari hubungan antar node atau aktor, SNA lebih sering digunakan untuk menentukan node sentral atau yang berperan penting di dalam sebuah network ${ }_{s}$ dengan menghitung beberapa nilai centrality diantaranya yang umum [9].

1) Degree centrality yaitu jumlah koneksi yang dimiliki sebuah node. Individu dengan relasi terbanyak adalah individu yang paling penting. Dapat dihitung menggunakan persamaan 1 sebagai berikut:

Dimana,

$$
C^{\prime} D(N i)=\frac{d(n i)}{g-1}(1)
$$

$C^{\prime}\left(n_{i}\right)=$ normalized degree centrality individu (node) $\mathrm{i}$

$\left(n_{i}\right) \quad=$ degree dari individu (node) $\mathrm{i}$

$g \quad=$ jumlah individu

2) Closeness centrality merupakan kedekatan suatu individu dengan individu yang lainnya. Individu dikatakan penting apabila dekat dengan individu yang lain. Closeness didasarkan pada kebalikan jarak dari tiap individu ke individu yang lain pada jaringan. Dapat dihitung menggunakan Persamaan 2 sebagai berikut:

Dimana,

$$
C_{C}\left(n_{i}\right)=\left[\sum_{j=1}^{g} d(n i, n j)\right.
$$

(ni) $\quad=$ closeness centrality individu (node) $\mathrm{i}$

$(n i, n j) \quad=$ jarak individu $\mathrm{i}$ ke $\mathrm{j}$ 
3) Betweeness centrality, menghitung jumlah jalan terpendek antara individu j dan $\mathrm{k}$ dimana individu i berada. Dapat dihitung menggunakan Persamaan 3 berikut:

Dimana,

$$
C_{B}(n i)=\sum_{j<k} \frac{g j k(n i)}{g j k}(3)
$$

(ni) = betweeness centrality individu (node) $\mathrm{i}$

(ni) = jumlah path dimana individu i berada

4) Eigenvector Centrality adalah ukuran yang memberikan bobot yang lebih tinggi pada node yang terhubung dengan node yang juga memiliki keterhubungan tinggi. Dapat dikatakan versi rekursif dari Degree Centrality.

Dimana,

$$
C(\beta)=\sum(a+\beta c j) A j i
$$

$\alpha=$ konstanta normalisasi (skala vektor).

$\beta=$ melambangkan seberapa banyak suatu node mempunyai bobot centrality dalam node yang juga memiliki nilai centrality yang tinggi.

\section{Perhitungan Properti Jaringan}

Dalam social network analysis mempunyai beberapa properti jaringan untuk membantu meningkatkan pengetahuan di setiap organisasi [10]. Properti jaringan pada SNA meliputi: size, density, average degree, diameter, clustering coefficient dan average path length yang masing-masing fungsinya dapat dilihat pada tabel 1.

Tabel 1 Properti Jaringan [11]

\begin{tabular}{|l|l|}
\hline \multicolumn{1}{|c|}{ Properti Jaringan } & \multicolumn{1}{c|}{ Fungsi } \\
\hline Size & Menunjukkan jumlah node dalam suatu jaringan \\
\hline Density & Kepadatan jaringan dalam suatu node. \\
\hline Modularity & $\begin{array}{l}\text { Menunjukkan bagaimana membentuk sebuah kelompok yang } \\
\text { tidak sama dalam suatu jaringan. }\end{array}$ \\
\hline Diameter & $\begin{array}{l}\text { Jalur terdekat dalam sebuah jaringan atau jarak terbesar } \\
\text { antara node. }\end{array}$ \\
\hline Average Degree & $\begin{array}{l}\text { Nilai rata-rata dari jumlah } \text { edge yang saling berhubungan } \\
\text { antar node. }\end{array}$ \\
\hline Average Path Length & $\begin{array}{l}\text { Average path length dilambangkan dengan <d Jarak rata- } \\
\text { rata antara node dalam sebuah jaringan }\end{array}$ \\
\hline Clustering Coefficient & $\begin{array}{l}\text { Sebuah node berhubungan dengan node lain di dalam } \\
\text { jaringan. Clustering coefficient dilambangkan dengan Ci, } \\
\text { apabila Ci=0, berarti node di sekitar node } \mathrm{i} \text { tidak berhubungan } \\
\text { satu sama lain. Sedangkan apabila Ci=1, berarti node di } \\
\text { sekitar node i semuanya saling terhubung. }\end{array}$ \\
\hline
\end{tabular}

Perhitungan properti jaringan merupakan suatu strategi baru yang dapat digunakan. Data percakapan yang terbentuk dalam jejaring sosial belum dimanfaatkan secara maksimal untuk menghimpun informasi terhapat pola komunikasi secara jelas. Dengan membandingkan properti jaringan yang dihasilkan otomatis melalui software gephi setelah menbandingkan properti jaringan pada jurusan, maka dipaparkan kesimpulan dari hasil analisis yang diperoleh.

\section{Analisis Data (Membandingkan Jaringan)}

Analis data didapatkan dari hasil perhitungan masing-masing properti jaringan, setelah hasil didapatkan maka dilakukan perbandingan agar dapat menunjukkan peringkat dari masingmasing jurusan yang mana lebih trend dan sering dibicarakan oleh generasi milenial. Analisis data bisa dimanfaatkan oleh perguruan tinggi untuk melihat celah dan minat generasi milenial 
mengenai jurusan yang mereka minati sehingga perguruan tinggi bisa membuat sebuah terobosan baru untuk menarik minat calon mahasiswa.

\section{HASIL DAN PEMBAHASAN}

\subsection{Karakteristik Data}

Data yang didapatkan sebanyak 2.894 data percakapan yang tersimpan dalam format .cvs. Data tersebut merupakan data yang belum diolah dan dilakukan preprocessing untuk mendapatkan struktur data yang sesuai dan data terbebas dari noise.dalam membentuk jaringan, diperlukan nama user dan nama jurusan yang di mention. Dengan demikian data lainnya tidak dibutuhkan sehingga data dilakukan pembersihan. Data yang telah dilakukan preprocessing memiliki struktur yang sesuai untuk dilakukan pengolahan lebih lanjut. Data tersebut kemudian di visualisasikan dan dilakukan pengukuran menggunakan bantuan perangkat lunak Gephi.

\begin{tabular}{|c|c|c|c|c|c|}
\hline \# & Id Tweet & Username & $\underline{\text { Tweet }}$ & Created At & Got At \\
\hline 1 & 2147483647 & @crescentmoonly & @zatalini_@collegemenfess misi, TI nya teknik informatika bukan? kalo boleh tau angkatan brp? & 04/01/202008:45 & $12 / 01 / 202002: 47$ \\
\hline 2 & 2147483647 & @qyotiegirl & @ @haaannabi_@collegemenfess samaan ni nder. pen ngambil ilmu gizi eh tp sm ortu disuruh teknik inf & 04/01/2020 03:50 & $12 / 01 / 202002: 47$ \\
\hline 3 & & @collegemenfess & [cm] disini ada kakak-kakak jurusan teknik informatika yang ga terlalu sibuk dan bersedia ditanyain ban & 6/01/202008:10 & 2/01/202002:47 \\
\hline 4 & 2147483647 & @terserahkmaj & @jasminsumardi @collegemenfess Eh gw bagi biaya buat maba tahun ini jurusan teknik informatika di & 08/01/202011:31 & 12/01/2020 02:47 \\
\hline 5 & 2147483647 & @MalangTimes & Dapat Kunjungan SMK PGRI Turen, Unikama Jalin MoU Guna Pengembangan SDM: Program Studi Teknik & 09/01/2020 02:34 & $12 / 01 / 202002: 47$ \\
\hline 6 & 2147483647 & @marshmxllww & @collegemenfess kl manajemen informatika dia hampir sama kyk SI. disitu ada matkul manajemennya & 09/01/2020 07:06 & $12 / 01 / 202002: 47$ \\
\hline 7 & 2147483647 & @pinguinberdebu & Teknik informatika=IImu Komputer Belajar ttg pengembangan software, Al, infrastruktur $\mathrm{Tl}$, dan pengo & 10/01/2020 03:57 & $12 / 01 / 202002: 47$ \\
\hline
\end{tabular}

Gambar 2 Data Sebelum Preprocessing

\begin{tabular}{|l|l|l|}
\hline username & to & jurusan \\
\hline crescentmoonly & zatalini_collegemenfess & teknik informatika \\
\hline qyotiegirl & haaannabi_collegemenfess & ilmu gizi teknik informatika \\
\hline collegemenfess & & teknik informatika \\
\hline terserahkmaj & jasminsumardi collegemenfess & teknik informatika \\
\hline MalangTimes & & teknik informatika \\
\hline marshmxllw & collegemenfess & manajemen informatika \\
\hline pinguinberdebu & & teknik informatika ilmu komputer pengembangan software \\
\hline
\end{tabular}

Gambar 3 Data seteleh Preprocessing

Dalam pengambilan data baik itu retweet, reply, maupun mention calon mahasiswa tidak hanya mention satu jurusan melainkan ada beberapa jurusan sehingga tidak dapat dipastikan jurusan yang mereka mention adalah pilihan utama dalam memilih jurusan, penelitian yang dilakukan hanya berfokus pada nama jurusan yang muncul.

Data yang didapatkan dapat membantu pihak perguruan tinggi dalam menganalisa tren jurusan yang popular di generasi milenial dan membuat sebuah terobosan baru agar calon mahasiswa tertarik untuk masuk ke dalam perguruan tinggi tersebut seperti yang telah dilakukan universitas binus yaitu membuat sebuah jurusan Game Application \& Technology [12], dan UPN "Veteran" Jakarta membuat terobosan baru yaitu membuka peluang bagi calon mahasiswa YouTube Content Creator yang memiliki minimal 10.000 subscriber dapat mendaftar melalui jalur prestasi [13]. Games dan content creator pada saat ini lagi trend dikalangan generasi milenial [3] bahkan banyak siswa atau mahasiswa yang putus sekolah atau kuliah karena ingin mengembangkan bakat mereka melalui game atau conten creator [14].

\subsection{Analisis pembuatan model jaringan jurusan}

Setelah melakukan proses filtering data, maka dilakukan pembuatan model jaringan tren milenial dalam pemilihan jurusan. Pembuatan visualisasi model jaringan ini dilakukan dengan bantuan software Gephi yang menggunakan undirected graph yang mana cara kerja dari graph ini tidak mempertimbangakan arah tujuan antar node. Jenis graph ini tidak melihat indegree (node yang dituju) dan out degree (node asal). Layout graf yang di pilih dalam pembuatan model jaringan ini adalah layout Yifan Hu Proportional yaitu suatu algoritma yang menyatukan bagianbagian yang baik dari algoritma yang diarahkan gaya dan algoritma multilevel untuk mengurangi kompleksitas algoritma. Ini merupakan salah satu algoritma yang bekerja sangat baik dengan 
jaringan besar. Dalam pembuatan model jaringan ada aktor atau influenser yang berperan penting dalam membentuk sebuah jaringan. Dalam menentukan pemeran kunci dapat menggunakan pengukuran centrality yang mana terbagi menjadi 4 centrality yaitu Degree centrality, Closeness centrality, betweeness centrality, Eigenvector Centrality. Dapat dilihat pada table 2 beberapa akun atau influencer yang berpengaruh terhadap terbentuknya jaringan jurusan.

Tabel 2 Perhitungan Centrality

\begin{tabular}{|l|l|l|l|l|}
\hline Node & Degree Centrality & \multicolumn{1}{|c|}{$\begin{array}{c}\text { Betweenees } \\
\text { Centrality }\end{array}$} & $\begin{array}{c}\text { Closeness } \\
\text { Centrality }\end{array}$ & $\begin{array}{c}\text { Eigenvector } \\
\text { Centrality }\end{array}$ \\
\hline @ ameliarizqaz & 378 & 857766.48 & 0.22401 & 1.0 \\
\hline @ zarazettirazr & 147 & 572631.64 & 0.180804 & 0.178683 \\
\hline @ e100ss & 142 & 216066.0 & 0.164059 & 0.169310 \\
\hline @ calonmedstud & 93 & 127267.35 & 0.163922 & 0.100864 \\
\hline @LokadataID & 78 & 118118.0 & 0.159598 & 0.070758 \\
\hline
\end{tabular}

Berdasarkan hasil keempat centrality, didapatkan bahwa pemeran kunci untuk membentuk jaringan jurusan adalah user ameliarizqaz. Nilai degree centrality yang dimiliki oleh ameliarizqaz yang didapatkan menggunakan rumus $C^{\prime} D(N i)=\frac{d(n i)}{g-1}$ menghasilkan nilai sebesar 378 hal ini menunjukan bahwa akun ameliarizqaz memiliki jumlah hubungan sebanyak 378 dengan akun lainnya. Semakin tinggi nilai degree centrality maka dapat dikatakan akun tersebut memiliki banyak hubungan dan dapat mempengaruhi akun lainnya. Centrality yang kedua yaitu betweenees centrality yang dapat di cari menggunakan rumus $C_{C}\left(n_{i}\right)=\left[\sum_{j=1}^{g} d(n i, n j)\right]^{-1}$ dalam pembentukan jaringan jurusan akun yang memiliki bentweenees centrality tertinggi ameliarizqaz yaitu dengan nilai 857766.48. Semakin tinggi nilai betweenees centrality maka menunjukan bahwa akun tersebut berperan sebagai perantaran antar aktor lainnya. User ameliarizqaz juga paling dekat dengan aktor lainnya sehingga memiliki nilai closeness centrality 0.22401 yang di hasilkan dari rumus $C_{B}(n i)=\sum_{j<k} \frac{g j k(n i)}{g j k}$. Tingginya nilai closeness centrality maka akun tersebut paling dekat dengan akun lainya sehingga apabila akun ameliarizqaz menyampaikan informasi maka akan lebih cepat menyebarnya. Akun yang memiliki nilai eigenvector yang tertinggi yaitu ameliarizqaz dengan menggunakan rumus $C(\beta)=\sum(a+\beta c j) A j i$ mendapatkan nilai 1.0. Akun yang memiliki nilai eigenvector centrality tertinggi menandakan bahwa user tersebut memiliki hubungan dengan banyak actor penting dalam sebuah jaringan.

Hasil tabel 2 mengenai akun yang berperan dalam pembuatan jaringan dengan adanya akun ini sebagai pemeran kunci maka mendapatkan 15 model jaringan yang mana menunjukan setiap actor atau node yang membicarakan mengenai jurusan yang mereka inginkan serta menunjukan hubungan antar node dan jaringannya. Adapun gambaran model jaringan yang terbentuk dari akun-akun yang membahas mengenai jurusan dapat dilihat pada gambar 4 bawah ini: 


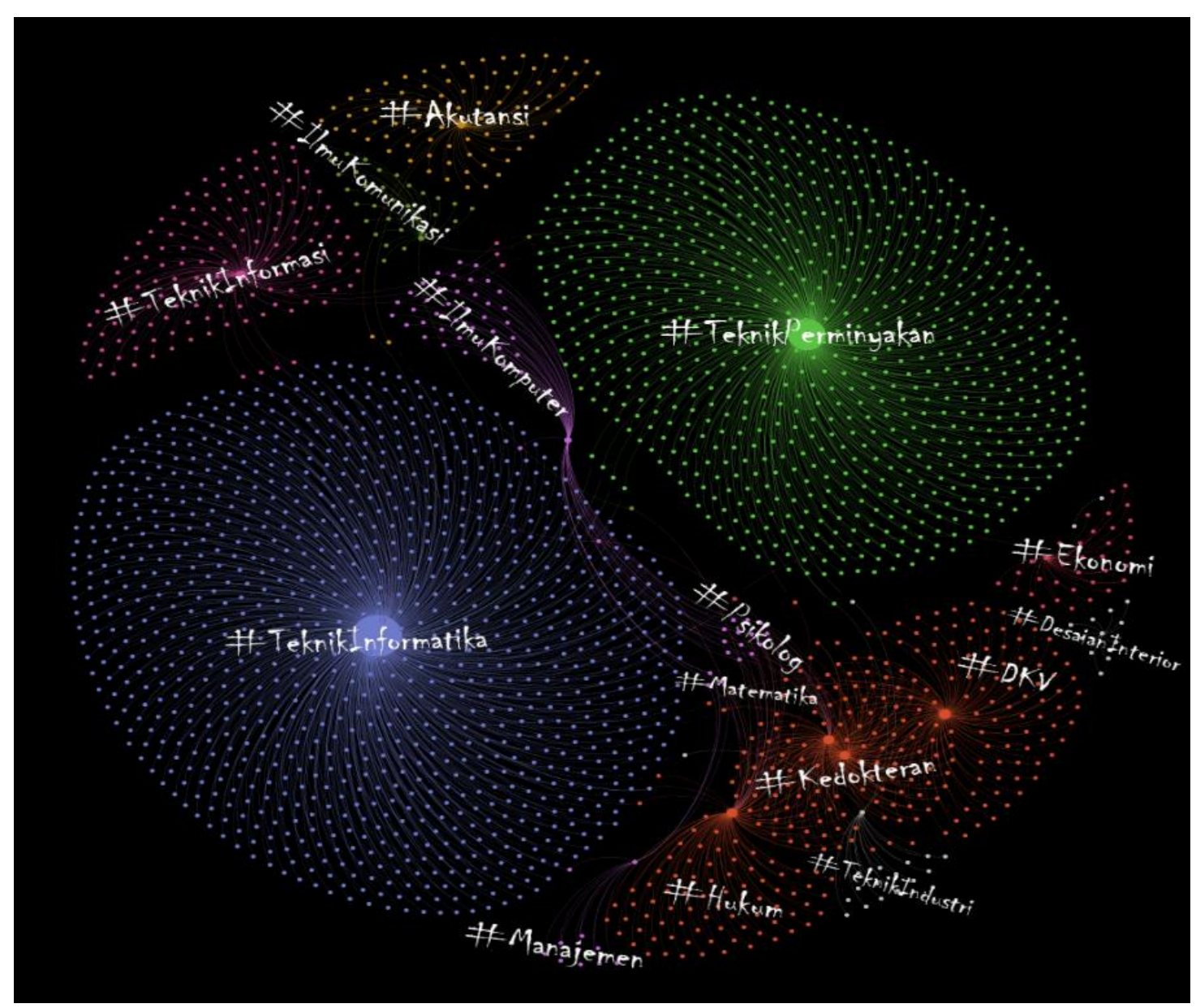

Gambar 4 Visualisasi Jaringan

\subsection{Perhitungan Properti Jaringan}

Setelah dilakukan pembuatan visualisasi model jaringan, diperlukan perhitungan properti jaringan agar dapat dianalisa lebih lanjut untuk dapat membandingkan data yang ada. Perhitungan dilakukan secara otomatis melalui software Gephi Tabel 3 merupakan perhitungan tersebut didapatkan hasil nilai dari masing-masing properti jaringan pada jaringan 15 jurusan.

Tabel 3 Perhitungan Properti Jaringan

\begin{tabular}{|l|l|l|l|l|l|l|l|}
\hline Properti Jaringan & \multicolumn{1}{|c|}{ Size } & Density & Modularity & Diameter & $\begin{array}{l}\text { Average } \\
\text { Degree }\end{array}$ & $\begin{array}{l}\text { Average Path } \\
\text { Length }\end{array}$ & $\begin{array}{c}\text { Clustering } \\
\text { Coefficient }\end{array}$ \\
\hline Teknik Informatika & $\begin{array}{l}\text { Nodes : } 1193 \\
\text { Edges : 2053 }\end{array}$ & 0.003 & 0.58 & 8 & 3.442 & 3.309 & 0.055 \\
\hline Teknik Industri & $\begin{array}{l}\text { Nodes : 48 } \\
\text { Edges: 66 }\end{array}$ & 0.059 & 0.511 & 4 & 2.75 & 2.152 & 0 \\
\hline Psikolog & $\begin{array}{l}\text { Nodes : } 25 \\
\text { Edges : } 36\end{array}$ & 0.12 & 0.247 & 4 & 2.88 & 1.898 & 0 \\
\hline Teknik Perminyakan & $\begin{array}{l}\text { Nodes : } 803 \\
\text { Edges : } 750\end{array}$ & 0.002 & 0.705 & 4 & 1.868 & 2.774 & 0 \\
\hline Matematika & $\begin{array}{l}\text { Nodes :23 } \\
\text { Edges :28 }\end{array}$ & 0.111 & 0.51 & 4 & 2.435 & 1.979 & 0 \\
\hline Kedokteran & $\begin{array}{l}\text { Nodes : } 175 \\
\text { Edges :283 }\end{array}$ & 0.019 & 0.476 & 4 & 3.234 & 2.261 & 0.079 \\
\hline Ilmu Komunikasi & $\begin{array}{l}\text { Nodes :85 } \\
\text { Edges :153 }\end{array}$ & 0.043 & 0.256 & 6 & 3.6 & 2.283 & 0 \\
\hline Ilmu Komputer & $\begin{array}{l}\text { Nodes :79 } \\
\text { Edges :118 }\end{array}$ & 0.038 & 0.453 & 8 & 2.987 & 3.102 & 0 \\
\hline
\end{tabular}




\begin{tabular}{|l|l|l|l|l|l|l|l|}
\hline Hukum & $\begin{array}{l}\text { Nodes : } 175 \\
\text { Edges :283 }\end{array}$ & 0.019 & 0.479 & 4 & 3.234 & 2.261 & 0.079 \\
\hline Ekonomi & $\begin{array}{l}\text { Nodes : } 60 \\
\text { Edges :76 }\end{array}$ & 0.043 & 0.636 & 8 & 2.533 & 4.202 & 0 \\
\hline Desaian Interior & $\begin{array}{l}\text { Nodes : } 14 \\
\text { Edges :20 }\end{array}$ & 0.22 & 0.18 & 2 & 2.857 & 1.655 & 0 \\
\hline Akutansi & $\begin{array}{l}\text { Nodes : } 190 \\
\text { Edges :299 }\end{array}$ & 0.017 & 0.494 & 6 & 3.147 & 3.089 & 0.02 \\
\hline Teknik Informasi & $\begin{array}{l}\text { Nodes : } 167 \\
\text { Edges : } 328\end{array}$ & 0.024 & 0.012 & 2 & 3.928 & 1.976 & 0.982 \\
\hline DKV & $\begin{array}{l}\text { Nodes : } 172 \\
\text { Edges :283 }\end{array}$ & 0.019 & 0.482 & 4 & 3.234 & 2.261 & 0.079 \\
\hline Manajemen & $\begin{array}{l}\text { Nodes : } 15 \\
\text { Edges : } 12\end{array}$ & 0.114 & 0.622 & 4 & 1.6 & 2.118 & 0 \\
\hline
\end{tabular}

Tabel diatas menunjukan perbandingan dari nilai properti jaringan yang berisikan interaksi user di media sosial twitter mengenai tren milenial dalam memilih jurusan dalam rentang waktu penelitian dari juli 2019 sampai dengan maret 2020. Properti yang dibandingkan pertama adalah size yang mana semakin besar node maka actor yang terjalin di dalam jaringan sosial semakin banyak. Hal seperti menandakah bahwa banyak aktor yang mengiginkan jurusan yang di bicarakan. Nilai size yang tertinggi adalah Teknik Informatika yaitu 1193 nodes yang menunjukan terdapat 1193 actor yang membicarakan di media sosial twitter disusul oleh Teknik Perminyakan yaitu sebanyak 803 nodes dan Akutansi sebanyak 190 nodes. Edges adalah interaksi yang terjadi antar aktor. Semakin tinggi nilai edges menunjukan bahwa banyak percakapan tentang jurusan tersebut di media sosial twitter. Teknik Informatika memiliki niali edge tertingi yaitu sebanyak 2053 edges dan yang kedua yaitu Teknik Perminyakan dengan 750 edges di susul Tenik Informasi dengan 328 edges.

Properti jaringan kedua adalah density semakin banyak aktor dalam jaringan akan menghasilkan nilai density yang besar. Semakin besar nilai density dari sebuah jaringan maka aktor-aktor yang ada di dalam jaringan lebih saling terhubung. Dari lima belas jurusan yang mendapatkan nilai density paling besar yaitu Desaian Interior yaitu 0.22 yang kedua yaitu Psikolog 0.12 dan yang ketiga yaitu Manajemen 0.114.

Properti jaringan yang ketiga adalah modularity. Semakin tinggi nilai modularity maka lebih jelas jaringan yang terbentuk. Setiap jaringan yang didapatkan dapat diartikan sebagai komunitas yang berbeda sehingga mendapatkan spsefikasi lebih terhadap produk di setiap komunitas. Jaringan jurusan yang di peringkat pertama nilai modularity adalah Teknik Informatika yaitu dengan nilai 0.58 selanjutnya Matematika dengan nilai 0.51 dan Desaian Interior dengan nilai 0.18 .

Properti jaringan yang keempat adalah diameter. Diameter yaitu jarak antar nodes dalam suatu jaringan. Semakin kecil diameter pada jaringan maka akan mudah node saling berinteraksi karena jarak antar node sangat pendek maka desaian interior dan Teknik Informasi di peringkat pertama dengan nilai 2 selanjutnya yaitu Teknik Industri, Psikolog, Teknik Perminyakan, Matematika, Kedokteran, Hukum, DKV dan Manajemen di peringkat kedua dengan nilai 4 dan Ilmu Komunikasi dan Akutansi di peringkat ketiga dengan nilai 6.

Properti jaringan kelima yaitu Average degree. Average degree memperlihatkan nilai antar hubungan aktor dalam sebuah jaringan social. Semakin besar nilai rata-rata average degree maka semakin baik karena setiap aktor dalam jaringan saling berhubungan, sehingga penyebaran informasi menjadi lebih luas. Jurusan yang mendapatkan nilai terbesar yaitu Teknik Informasi dengan nilai 3.928 selanjutnya yaitu jurusan Ilmu Komunikasi dengan nilai 3.6 dan jurusan Teknik Informatika dengan nilai 3.442. 
Properti jaringan keenam Average path length yaitu semakin sedikit rata-rata jaringan akun yang dilewati maka semakin baik karena setiap jaringan mempunyai hubungan yang kuat. Nilai dari average path length terkecil adalah pada interaksi user mengenai jurusan Desaian Interior dengan nilai 1.655 selanjutnya yaitu Psikolog dengan nilai 1.898 dan jurusan Teknik Informasi dengan nilai 1.976 .

Properti jaringan yang terakhir adalah clustering coefficient. Clustering coefficient menunjukan actor yang berkaitan dalam properti jaringan. Actor dalam properti jaringan pada jurusan yang paling tinggi yaitu Teknik Informatika yang mana actor didalamnya saling terkait satu dengan yang lainnya, maka informasi yang dibicarakan lebih awal untuk diketahui.

\section{KESIMPULAN}

Berdasarkan hasil dari tabel dalam perhitungan properti jaringan didapatkan nilai jaringan dari setiap jurusan. Setelah dilakukan perhitungan jurusan yang paling banyak mendapatkan nilai tertinggi yaitu Teknik Informatika dengan total lima dari tujuh properti jaringan. Teknik Informatika mendapatkan yang tinggi mengenai nodes yang artinya bahwa banyak pengguna atau generasi milenial yang membahas mengenai Teknik Informatika di media sosial twitter, dan edges yang membuktikan banyaknya interaksi antar user mengenai jurusan Teknik Informatika, Average Degree menunjukan setiap user atau aktor dalam jaringan mendapatkan nilai banyak yang saling keterkaitan sehingga memperluas penyebaran informasi mengenai jurusan Teknik Informatika.

\section{SARAN}

Penelitian ke depan, perhitungan property jaringan dapat dilakukan lebih dari satu software tidak hanya menggunakan software Gephi saja. Hal ini agar dapat menjadi pembanding dan dapat mengukur keakuratan dari perhitungan model jaringan itu sendiri. Penelitian ini hanya membahas terkait dengan jurusan yang paling di mention pada twitter, untuk itu perlu adanya penelitian lebih lanjut. Penelitian yang disarankan untuk dilanjutkan adalah terkait dengan promosi kampus atau jurusan berdasarkan data-data yang didapatkan dalam penelitian ini dengan menggunakan metode yang sama sebagai sarana memperkaya sumber pustaka dan pengetahuan yang dibutuhkan dalam penelitian terkait untuk metode social network analysis.

\section{DAFTAR PUSTAKA}

[1] P. Pemerintah, "UNDANG-UNDANG REPUBLIK INDONESIA NOMOR 20 TAHUN 2003 TENTANG SISTEM PENDIDIKAN NASIONAL," hal. 6-8, 2003, doi: 10.16309/j.cnki.issn.1007-1776.2003.03.004.

[2] Yuswohady, "Millennial Trends," yuswohady.com, 2016. [Daring]. Tersedia pada: https://www.yuswohady.com/2016/01/17/millennial-trends-2016/. [Diakses: 13-Jan2020].

[3] J. N. Mahameruaji, L. Puspitasari, E. Rosfiantika, dan D. Rahmawan, "Bisnis Vlogging dalam Industri Media Digital di Indonesia," Jurnal ILMU KOMUNIKASI, vol. 15, no. 1, hal. 61-74, 2018, doi: 10.24002/jik.v15i1.1007.

[4] Kemenristekdikti, "Indonesia Higher Education Statistical Year Book 2018," Chemistry A European Journal, vol. 15, no. 21, hal. 1-7, 2018, doi: 10.1002/chem.200802548.

[5] A. D. Sukmawan, "Sistem Pendukung Keputusan Pemilihan Jurusan Di Smu," Seminar Nasional Informatika 2008 (semnasIF 2008) UPN "Veteran" Yogyakarta, 24 Mei 2008 ISSN: 1979-2328, vol. 2008, hal. 213-218, 2008.

[6] L. Freeman, "The Development of Social Network Analysis," Jan 2004. 
[7] E. Otte dan R. Rousseau, "Social network analysis: a powerful strategy, also for the information sciences," Journal of Information Science, vol. 28, no. 6, hal. 441-453, Des 2002, doi: 10.1177/016555150202800601.

[8] R. Feldman, J. Sanger, dan others, The text mining handbook: advanced approaches in analyzing unstructured data. Cambridge university press, 2007.

[9] J. Li, Y. Chen, dan Y. Lin, "Research on traffic layout based on social network analysis," in 2010 2nd International Conference on Education Technology and Computer, 2010, vol. 1, hal. V1--284.

[10] A. Alamsyah, "The Role of Social Network Analysis for Knowledge Management," Jurnal Manajemen Indonesia, vol. 12, no. 4, hal. 309-314, 2013.

[11] M. S. Setatama dan D. Tricahyono, "Implementasi Social Network Analysis pada Penyebaran Country Branding 'Wonderful Indonesia," Indonesian Journal on Computing (Indo-JC), vol. 2, no. 2, hal. 91, 2017, doi: 10.21108/indojc.2017.2.2.183.

[12] Binus.ac.id, "Jurusan Game Application \& Technology BINUS UNIVERSITY Menjalin Kerjasama Dengan Industri Game Dunia | BINUS UNIVERSITY,” official binus, 2015. [Daring]. Tersedia pada: https://binus.ac.id/2015/09/jurusan-game-applicationtechnology-binus-university-menjalin-kerjasama-dengan-industri-game-dunia/. [Diakses: 01-Feb-2020].

[13] Www.upnvj.ac.id, "UPNVJ Gelar Uji Keterampilan untuk YouTube Content Creator Jalur Prestasi SEMA 2019 - UPN Veteran Jakarta," upnvj official, 2019. [Daring]. Tersedia pada: https://www.upnvj.ac.id/id/berita/2019/07/upnvj-gelar-uji-keterampilan-untukyoutube-content-creator-jalur-prestasi-sema-2019.html. [Diakses: 01-Feb-2020].

[14] "Tolong! Terancam Drop Out Akibat Kecanduan Game." [Daring]. Tersedia pada: https://inet.detik.com/konsultasi-cyberlife/d-3308834/tolong-terancam-drop-out-akibatkecanduan-game. [Diakses: 04-Jun-2020]. 